\title{
Effect of Interval Between Actuations of Albuterol Hydrofluoroalkane Pressurized Metered-Dose Inhalers on Their Aerosol Characteristics
}

\author{
Ariel Berlinski MD and David Pennington
}

\begin{abstract}
BACKGROUND: Albuterol hydrofluoroalkane (HFA) either alone or with a valved holding chamber is used to treat bronchoconstriction. Delays between actuation and inhalation are common. Currently, the recommended interval between actuations of an albuterol HFA is $60 \mathrm{~s}$. Using a shorter interval when multiple actuations are ordered will improve productivity in the hospital setting. METHODS: We studied aerosol characteristics of albuterol HFA (Ventolin, ProAir, and Proventil) with a cascade impactor calibrated at $30 \mathrm{~L} / \mathrm{min}$. We studied pressurized metered-dose inhalers (pMDI) alone, coupled to a nonelectrostatic valved holding chamber, and coupled to the valved holding chamber but introducing a 10-s delay between actuation and measurement. We tested intervals between actuations of 60, 30, and $15 \mathrm{~s}$ (not for delay scenario). The variable of most interest was fine-particle mass. Albuterol was measured by spectrophotometer (276 nm). RESULTS: Variations in fine-particle mass from 60-s values were $<15 \%$ for Ventolin and ProAir for all conditions tested and for Proventil with a valved holding chamber. Variations in fine-particle mass from 60-s values were $>15 \%$ for Proventil (pMDI alone with a 30-s interval and pMDI/valved holding chamber with delay and a 30-s interval). Adding a valved holding chamber increased fine-particle mass for all brands (ProAir 7-12\%, Ventolin 26-35\%, and Proventil 44-47\%). The introduction of a 10-s delay reduced fine-particle mass for all brands (ProAir 34-39\%, Ventolin 39-42\%, and Proventil 27-32\%). Comparison of fine-particle mass among brands showed that Proventil was > ProAir > Ventolin. CONCLUSIONS: Decreasing the interval between actuations from 60 to 30 and $15 \mathrm{~s}$ does not seem to affect the aerosol characteristics of ProAir and Ventolin. Although some changes were noticed for Proventil, the pMDI outperformed Ventolin that had the lowest fineparticle mass. The use of a valved holding chamber increased fine-particle mass, but introducing a 10-s delay between actuation and inhalation significantly reduced fine-particle mass. Key words: drug delivery; aerosol characteristics; valved holding chamber; metered dose inhaler; particle size; delay. [Respir Care 2017;62(9):1123-1130. ㅇ 2017 Daedalus Enterprises]
\end{abstract}

\section{Introduction}

Asthma is a highly prevalent disease affecting approximately 6 million children in the United States. ${ }^{1}$ Almost

Dr Berlinski and Mr Pennington are affiliated with the University of Arkansas for Medical Sciences, College of Medicine. Dr Berlinski is also affiliated with the Pediatric Pulmonology Division, UAMS, and the Pediatric Aerosol Research Laboratory, Arkansas Children's Research Institute, Little Rock, Arkansas.

Dr Berlinski presented a version of this paper at the European Respiratory Society Meeting, held September 6, 2016, in London, United Kingdom.

Dr Berlinski has disclosed relationships with AbbVie, Anthera, Aptalis Pharma, Cempra, Janssen Research and Development, Gilead, National
$60 \%$ of these patients experienced at least one asthma attack, and almost 137,000 patients were discharged with a diagnosis of asthma from hospitals in the United States during 2010. ${ }^{1}$ The National Asthma Education and Prevention Program Expert Panel Report 3 defines asthma as "a complex disorder characterized by variable and recurring symptoms, air-flow obstruction, bronchial hyper-responsiveness, and an underlying inflammation."2 Inhaled

Institutes of Health, Novartis, Therapeutic Development Network, Vertex, and the International Pharmaceutical Aerosol Consortium on Regulation and Science. Mr Pennington was supported by a University of Arkansas for Medical Sciences College of Medicine Research Grant. Mr Pennington has disclosed no conflicts of interest. 
bronchodilators are used for management of acute episodes of bronchoconstriction. ${ }^{2}$

Several studies have found that aerosol delivery via pressurized metered-dose inhalers (pMDI) and via pMDI with

\section{See the Related Editorial on Page 1224}

a valved holding chamber are as efficacious as nebulized albuterol for the treatment of asthma exacerbations in adults and children, respectively. ${ }^{3}$ Length of treatment of a nebulized bronchodilator is typically around $10-15 \mathrm{~min}$ but is actually 5-10 min longer when preparation and cleaning are taken into account. Manufacturers of albuterol in the United States recommend a 1-min interval between actuations. ${ }^{4-6}$ Therefore, if large number of actuations of albuterol pMDI are prescribed, the length of treatment might become similar to that of a nebulizer treatment. Being able to administer albuterol pMDI with a shorter interval between actuations would allow greater productivity in the hospital setting. Previously, Hautmann et $\mathrm{al}^{7}$ reported that the fine-particle mass increased from pMDI, and pMDI with a valved holding chamber increased when the interval between actuations increased from 15 to $120 \mathrm{~s}$. However, they provided limited data on the characterization of the aerosols. Clark et $\mathrm{al}^{8}$ reported that a delay between actuation and inhalation resulted in a decrease in lung bioavailability of albuterol pMDI delivered with a valved holding chamber. Delays between actuation and inhalation are common during real-life administration of pMDI with a valved holding chamber. Therefore, it is clinically relevant to investigate the effect of the delay on the aerosol characteristics of albuterol pMDI. Several authors have reported differences in the aerosol characteristics of different brands; therefore, evaluating all available brands is also relevant. ${ }^{7,9}$

In this study, we compared the aerosol characteristics of 3 different brands of albuterol hydrofluoroalkane (HFA) pMDI alone, with a valved holding chamber, and with a valved holding chamber introducing a 10 -s delay between actuation and inhalation. We hypothesized that (1) there would be differences in the characteristics of the aerosol generated by each brand of inhaler actuated at different time intervals, (2) the use of a valved holding chamber would eliminate those differences, and (3) the introduction of a 10-s delay between actuation and measurement could change aerosol characteristics.

\footnotetext{
Correspondence: Ariel Berlinski MD, Pediatric Pulmonology Division, University of Arkansas for Medical Sciences, College of Medicine, 1 Children's Way, Slot 512-17, Little Rock, AR 72202. E-mail: BerlinskiAriel@uams.edu.
}

DOI: $10.4187 /$ respcare.05528

\section{QUICK LOOK}

\section{Current knowledge}

Currently, the recommended interval between actuations of an albuterol hydrofluoroalkane is $60 \mathrm{~s}$. Using a shorter interval when multiple actuations are ordered will improve productivity in the hospital setting.

\section{What this paper contributes to our knowledge}

Intervals between actuations of albuterol hydrofluoroalkane of 30 or $15 \mathrm{~s}$ produced an aerosol with similar characteristics to the one with a 60 -s interval. The addition of a valved holding chamber increased the fineparticle mass. Conversely, a delay between actuation of pressurized metered-dose inhaler/valved holding chamber and testing resulted in a significant decrease in fine-particle mass.

\section{Methods}

The experiments were performed at the Pediatric Aerosol Research Laboratory at Arkansas Children's Research Institute in Little Rock, Arkansas. The study comprised 3 parts. Particle size distribution was determined for the pMDI alone (part A), pMDI with a valved holding chamber (part $\mathrm{B}$ ), and pMDI with a valved holding chamber and a 10-s delay between actuation and measurement (part C).

\section{The pMDI and the Valved Holding Chamber}

We tested 4 new units of albuterol HFA of 3 different brands. ProAir HFA (Teva Specialty Pharmaceuticals, Horsham, Pennsylvania) and Ventolin HFA (GlaxoSmithKline, Philadelphia, Pennsylvania) have incorporated counters to monitor the remaining number of actuations. Proventil HFA (3M Health Care, Loughborough, United Kingdom) was also tested. Since the latter did not have a counter, the number of actuations was recorded in the laboratory notebook. Four new, nonelectrostatic valved holding chambers (AeroChamber Plus Flow-Vu, Monaghan Medical, Plattsburgh, New York) with mouthpiece were used for parts B and C of the study.

\section{Study Design}

Four pMDIs of each brand were tested for the scenarios. During part A, pMDIs were tested without a valved holding chamber, and 3 different timing intervals between actuations were studied (15, 30, and $60 \mathrm{~s})$. During part B, pMDIs were tested with a valved holding chamber and the same time intervals between actuations used in part A. Part 


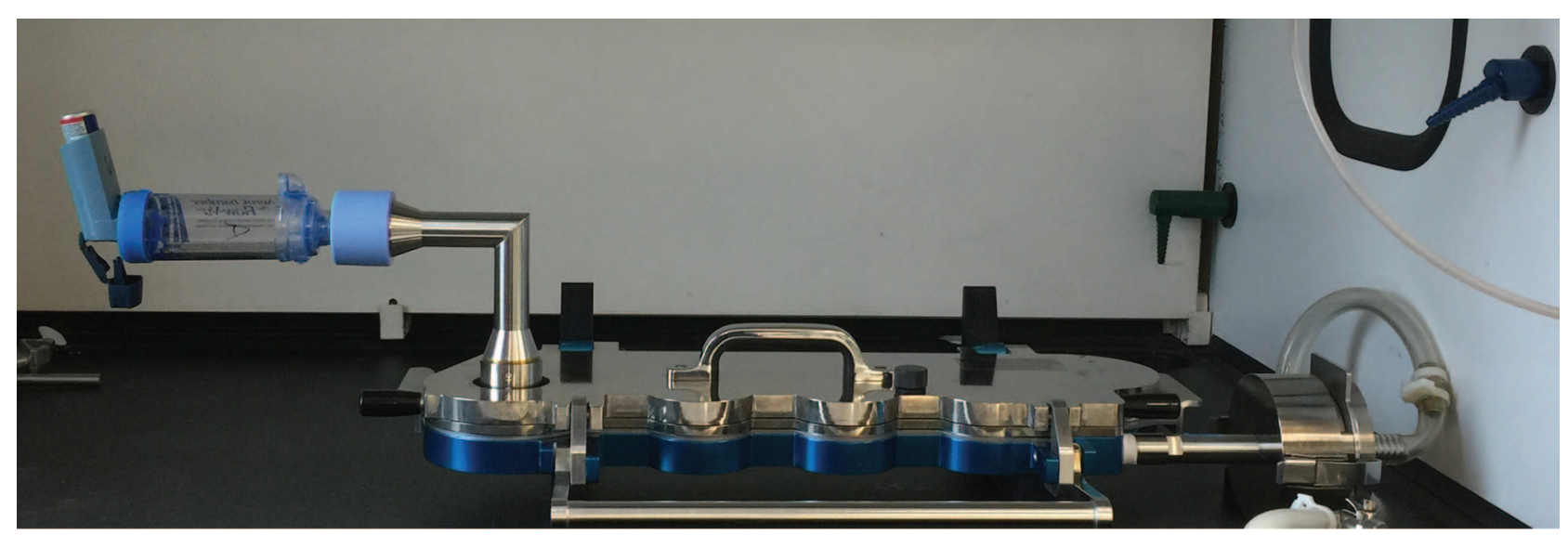

Fig. 1. Investigational setup used to measure particle size of albuterol hydrofluroalkane.

C was similar to part B, except that a 10-s delay between actuation and connection of the valved holding chamber to the cascade impactor was introduced. Also during part C, the only timing intervals between actuations that were tested were 30 and $60 \mathrm{~s}$.

\section{Procedure}

A Next Generation Impactor (model 170 NGI, MSP Corporation, Shoreview, Minnesota) assembled with internal and external filters was used. ${ }^{10}$ At the beginning of each procedure, the temperature (median $23^{\circ} \mathrm{C}$ [95\% CI $\left.\left.23-23.5^{\circ} \mathrm{C}\right]\right)$ and humidity $(47 \%$ [95\% CI $\left.44-47 \%]\right)$ were documented, and the impactor was calibrated to $30 \mathrm{~L} / \mathrm{min}$ using a mass flow meter (Mass Flowmeter 4043, TSI, Shoreview, Minnesota). A silicon adapter was used to connect the throat of the NGI to either the pMDI or the valved holding chamber. Each pMDI was primed with 4 actuations at the beginning of each testing day. During part A, the impactor was powered on, and the pMDI was shaken for $5 \mathrm{~s}$ and then connected to the adapter and actuated once, with $3 \mathrm{~s}$ elapsing between the last shake and the actuation. The pMDI was removed after $5 \mathrm{~s}$. The procedure was repeated 9 more times for a total of 10 actuations. The canisters were weighed at the beginning and at the end of the 10 actuations for quality control. Interval periods between actuations of 15, 30, and $60 \mathrm{~s}$ were tested. During part B, the pMDI was placed in the posterior opening of the valved holding chamber and shaken for $5 \mathrm{~s}$. The system was then connected to the impactor with $3 \mathrm{~s}$ elapsing between the last shake and the actuation (Fig. 1). The pMDI/valved holding chamber was removed after $5 \mathrm{~s}$. The procedure was repeated 9 more times for a total of 10 actuations. The canisters were weighed at the beginning and at the end of the 10 actuations for quality control. Interval periods between actuations of 15 , 30 , and $60 \mathrm{~s}$ were tested. During part C, the pMDI connected to the valved holding chamber was shaken for $5 \mathrm{~s}$ and actu- ated once, with $3 \mathrm{~s}$ elapsing from the last shake and the actuation. A 10-s interval was introduced between actuation of the pMDI and connection to the impactor. The $\mathrm{pMDI} / \mathrm{valved}$ holding chamber was removed after $5 \mathrm{~s}$. The procedure was repeated 9 more times for a total of 10 actuations. The canisters were weighed at the beginning and at the end of the 10 actuations for quality control. Interval periods between actuations of 30-60 s were tested. The median $(99 \% \mathrm{CI})$ pooled differences in canister weight were $1.020 \mathrm{~g}(1.009-1.024 \mathrm{~g})$, $0.453 \mathrm{~g}(0.447-0.458 \mathrm{~g})$, and $0.400 \mathrm{~g}(0.374-0.412 \mathrm{~g})$ for Ventolin, ProAir, and Proventil, respectively.

The impactor was disassembled at the end of 10 actuations, and the throat, cups, and filters were eluded with $10 \mathrm{~mL}$ of double-distilled water. Valved holding chambers were cleaned after each series of 10 runs, and they were tested for the presence of albuterol before the following test. The plastic actuator of the pMDI was also flushed with double-distilled water and dried with compressed air. All washings were tested for albuterol concentration using spectrophotometry (Biomate $3 \mathrm{UV}$-visible spectrophotometer, Thermo Fisher Scientific, Waltham, Massachusetts) at $276 \mathrm{~nm}$.

Mass median aerodynamic diameter (MMAD), geometric standard deviation (GSD), and percentage of drug mass associated with particles $<5 \mu \mathrm{m}$ and between 1 and $3 \mu \mathrm{m}$ were calculated using CITDAS 3.1 software (Copley Scientific, Nottingham, United Kingdom). Fine-particle mass was calculated as the amount of drug captured in stages 4-7 of the impactor. ${ }^{7}$ Variation was calculated as follows: (variable at 30 or $15 \mathrm{~s}-$ variable at $60 \mathrm{~s}$ )/variable at $60 \mathrm{~s} \times$ 100. Variations in FPM, percentage $<5 \mu \mathrm{m}$, and percentage $1-3 \mu \mathrm{m}$ of $\leq 15 \%$ were considered acceptable. ${ }^{11}$

\section{Statistical Analysis}

Comparisons between variables obtained with the same $\mathrm{pMDI} / \mathrm{valved}$ holding chamber and $\mathrm{pMDI} / \mathrm{valved}$ holding chamber with 10-s delay were done with a paired $t$ test 


\section{Timing of Albuterol HFA Inhaler Actuations}

Table 1. Aerosol Characteristics of Pressurized Metered-Dose Inhaler Alone Actuated at Different Interval Periods*

\begin{tabular}{|c|c|c|c|c|c|}
\hline Dose & MMAD $(\mu \mathrm{m})$ & GSD & $<5 \mu \mathrm{m}(\%)$ & $1-3 \mu \mathrm{m}(\%)$ & FPM $(\mu \mathrm{g})$ \\
\hline Ventolin, $60 \mathrm{~s}$ & $2.34 \pm 0.06$ & $1.49 \pm 0.01$ & $44 \pm 1.6$ & $32.2 \pm 1$ & $299 \pm 16$ \\
\hline Ventolin, $30 \mathrm{~s}$ & $2.29 \pm 0.08$ & $1.54 \pm 0.06$ & $45.4 \pm 2.1$ & $31.5 \pm 2.2$ & $300 \pm 18$ \\
\hline Ventolin, $15 \mathrm{~s}$ & $2.29 \pm 0.09$ & $1.61 \pm 0.04 *$ & $43.6 \pm 2$ & $29.7 \pm 1.4$ & $290 \pm 11$ \\
\hline ProAir, $60 \mathrm{~s}$ & $2.12 \pm 0.03$ & $1.41 \pm 0.01$ & $69.7 \pm 0.2$ & $53 \pm 0.7$ & $544 \pm 18$ \\
\hline ProAir, $30 \mathrm{~s}$ & $2.25 \pm 0.01 *$ & $1.44 \pm 0.02 *$ & $65.3 \pm 1.7 \dagger$ & $47.2 \pm 1.2 \dagger$ & $508 \pm 9 \dagger$ \\
\hline ProAir, $15 \mathrm{~s}$ & $2.29 \pm 0.01 *$ & $1.40 \pm 0.01$ & $66.2 \pm 1.8 \dagger$ & $50.1 \pm 2 \dagger$ & $493 \pm 15 \dagger$ \\
\hline Proventil, $60 \mathrm{~s}$ & $2.16 \pm 0.06$ & $1.43 \pm 0.07$ & $68.2 \pm 4.1$ & $51.5 \pm 0.6$ & $413 \pm 19$ \\
\hline Proventil, $30 \mathrm{~s}$ & $2.20 \pm 0.04$ & $1.45 \pm 0.06$ & $56.6 \pm 2.7 * \dagger$ & $46.1 \pm 1.8 \dagger$ & $350 \pm 16^{* \dagger}$ \\
\hline Proventil, $15 \mathrm{~s}$ & $2.16 \pm 0.02$ & $1.56 \pm 0.06$ & $57.7 \pm 2.9 * \dagger$ & $39.1 \pm 2.2 * \dagger$ & $424 \pm 33$ \\
\hline \multicolumn{6}{|c|}{$\begin{array}{l}\text { Results are mean } \pm \text { SD. } \\
* \text { Different from } 60 \text {-s interval }(P<.05) \text {. } \\
\dagger \text { Variations from } 60 \text {-s values are }>15 \% \text {. } \\
\text { MMAD = mass median aerodynamic diameter } \\
\text { GSD }=\text { geometric standard deviation } \\
\text { FPM = fine-particle mass }\end{array}$} \\
\hline
\end{tabular}

with unequal variance. Comparisons among variables obtained with the same pMDI brand at difference time intervals and scenarios were done with analysis of variance for repeated measures followed by a Dunnett test when necessary. Comparison of fine-particle mass among brands at each scenario was done with analysis of variance for repeated measures followed by the Tukey test when necessary. A $P$ value of $<.05$ was considered statistically significant. A statistical software package was used for all of the calculations (Kaleidagraph 4.53, Synergy Software, Reading, Pennsylvania).

\section{Results}

\section{pMDI Alone}

There were no significant differences in MMAD among the 3 time intervals for Ventolin $(P=.32)$ and Proventil $(P=.26)$ (Table 1). However, MMAD for ProAir was larger with 30-s $(P<.001)$ and 15-s $(P<.001)$ intervals when compared with 60-s intervals. The differences between the smallest and largest MMAD were 0.23, 0.21, and $0.14 \mu \mathrm{m}$ for Ventolin, ProAir, and Proventil, respectively. The differences do not appear to be clinically relevant.

There were no significant differences in GSD among the 3 time intervals for Proventil $(P=.11)$. However, GSD for ProAir with $15 \mathrm{~s}$ was similar to the 60-s interval $(P=.057)$, and the 30-s was larger than the 60-s interval $(P=.005)$. In addition, GSD for Ventolin for $30 \mathrm{~s}$ was similar to the 60-s interval $(P=.30)$, and the 15 -s was larger than the 60-s interval $(P=.02)$. The differences between the smallest and largest GSD were 0.18, 0.07, and 0.24 for Ventolin, ProAir, and Proventil, respectively. All aerosols were heterodisperse, and the differences do not appear to be clinically relevant.
There were no significant differences in percentage $<5 \mu \mathrm{m}$ among the 3 time intervals for Ventolin $(P=.46)$. However, the percentage $<5 \mu \mathrm{m}$ for ProAir was larger at a 60-s interval than at 30 and $15 \mathrm{~s}(P=.004$ and $P=.01$, respectively). Similar behavior was noted for Proventil ( $P=.01$ and $P=.02$ for 30 and $15 \mathrm{~s}$, respectively). Variations from 60 -s values were $<15 \%$ for Ventolin and ProAir but $>15 \%$ for Proventil.

There were no significant differences in percentage 1-3 $\mu \mathrm{m}$ among the 3 time intervals for Ventolin $(P=.12)$. However, for ProAir $(P<.001$ and $P=.006)$ and Proventil $(P=.02$ and $P<.001)$, the 60 -s interval had a larger percentage 1-3 $\mu \mathrm{m}$ than 30 - and 15-s intervals, respectively. Variations from 60 -s values were $<15 \%$ for Ventolin and ProAir, but $>15 \%$ for Proventil at the 15-s interval.

There were no significant differences in fine-particle mass among the different actuation intervals for Ventolin $(P=.71)$ (Fig. 2). ProAir showed a decrease in fineparticle mass with a decrease in actuation intervals ( $P=.031$ and $P=.01$ for 30 - and 15 -s intervals, respectively). Proventil showed a decrease in fine-particle mass for the 30-s, but not for the $15-\mathrm{s}$, interval $(P=.02$ and $P=.80$, respectively). Variations from 60-s values were $<15 \%$ for Ventolin, Proventil, and ProAir, except for Proventil at the 30-s interval. Comparison of fine-particle mass among brands showed that Proventil was $>$ ProAir $>$ Ventolin at all tested intervals $(P \leq .004)$.

\section{pMDI With Valved Holding Chamber}

There were no significant differences in MMAD among the 3 time intervals for Ventolin, ProAir, and Proventil ( $P=.64, P=.99, P=.26$, respectively) (Table 2$)$. The differences between the smallest and largest MMAD were 
0.20, 0.25, and $0.26 \mu \mathrm{m}$ for Ventolin, ProAir, and Proventil, respectively. The differences do not appear to be clinically relevant.

There were no significant differences in GSD among the 3 time intervals for ProAir $(P=.35)$ and Proventil $(P=.23)$. The GSD for Ventolin with the 15 -s interval was similar to the 60 -s interval $(P=.95)$ but larger for the 30 -s interval $(P=.02)$. The differences between the smallest and largest GSD were $0.16,0.08$, and 0.22 for Ventolin, ProAir, and Proventil, respectively. All aerosols were

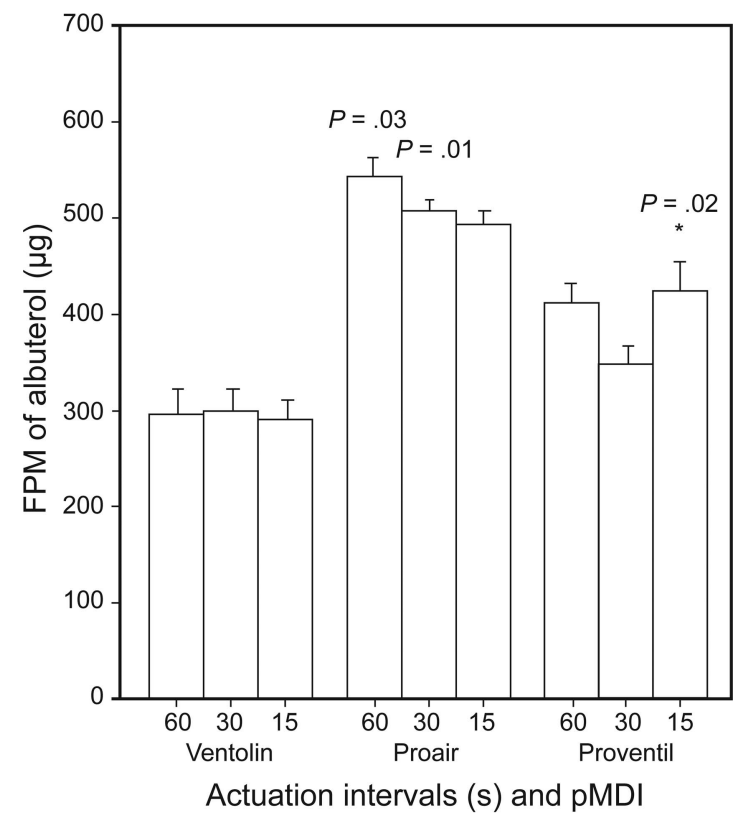

Fig. 2. Fine-particle mass (FPM) of albuterol hydrofluroalkane pressurized metered-dose inhaler (pMDI) alone. Bars show means, and error bars represent SD. $P$ values are fine-particle mass difference from a 60 -s interval. * Variation from $60 \mathrm{~s}$ is $>15 \%$. heterodisperse, and the differences do not appear to be clinically relevant.

There were no significant differences in percentage $<5 \mu \mathrm{m}$ among the 3 time intervals for $\operatorname{ProAir}(P=.16)$ and Proventil $(P=.64)$. However, the percentage $<5 \mu \mathrm{m}$ for Ventolin was similar for 60- and 30-s intervals $(P=.58)$ but was larger for the 15- than for the 60-s interval $(P=.02)$. Variations from 60 -s values were $<15 \%$ for all brands.

There were no significant differences in percentage 1-3 $\mu \mathrm{m}$ among the 3 time intervals for Ventolin $(P=.09)$, ProAir $(P=.29)$ and Proventil $(P=.44)$. Variations from 60 -s values were $<15 \%$ for all brands.

There were no significant differences in fine-particle mass among the different actuation intervals for Ventolin $(P=.15)$ and ProAir $(P=.059)$ (Fig. 3). Proventil showed a decrease in fine-particle mass for the 30-s, but not for the 15 -s, interval $(P=.02$ and $P=.99$, respectively). Variations from 60 -s values were $<15 \%$ for all brands. Comparison of fine-particle mass among brands showed that Proventil $=$ ProAir $(P=.50)>$ Ventolin at 60-s intervals $(P<.001)$. The addition of the valved holding chamber resulted in a modest increase in fine-particle mass for ProAir (7-12\%) and in a significant increase for Ventolin (26-35\%) and Proventil (44-47\%). Comparison of fineparticle mass among brands showed that Proventil was $>$ ProAir $>$ Ventolin at 30 - and 15 -s intervals $(P \leq .02)$.

\section{pMDI With Valved Holding Chamber and Delay}

There were no significant differences in MMAD between the 2 time intervals for Ventolin $(P=.90)$, and ProAir $(P=.07)$ (Table 3). However, MMAD for Proventil was larger for the 30 -s interval $(P=.02)$. The differences between the smallest and largest MMAD were 0.18 , 0.20 , and $0.16 \mu \mathrm{m}$ for Ventolin, ProAir, and Proventil,

Table 2. Aerosol Characteristics of Pressurized Metered-Dose Inhaler Coupled to a Valved Holding Chamber Actuated at Different Interval Periods

\begin{tabular}{|c|c|c|c|c|c|}
\hline Dose & $\operatorname{MMAD}(\mu \mathrm{m})$ & GSD & $<5 \mu \mathrm{m}(\%)$ & $1-3 \mu \mathrm{m}(\%)$ & FPM $(\mu \mathrm{g})$ \\
\hline Ventolin, $60 \mathrm{~s}$ & $2.17 \pm 0.06$ & $1.45 \pm 0.01$ & $94.2 \pm 1.8$ & $70.8 \pm 2.7$ & $403 \pm 23$ \\
\hline Ventolin, $30 \mathrm{~s}$ & $2.10 \pm 0.06$ & $1.54 \pm 0.05^{*}$ & $95.2 \pm 2.7$ & $65.5 \pm 6.5$ & $394 \pm 24$ \\
\hline Ventolin, $15 \mathrm{~s}$ & $2.12 \pm 0.12$ & $1.46 \pm 0.04$ & $97.7 \pm 0.1 *$ & $70.9 \pm 5.5$ & $366 \pm 21$ \\
\hline ProAir, $60 \mathrm{~s}$ & $2.29 \pm 0.10$ & $1.40 \pm 0.02$ & $99.7 \pm 0.1$ & $72.9 \pm 0$ & $581 \pm 30$ \\
\hline ProAir, $30 \mathrm{~s}$ & $2.29 \pm 0.04$ & $1.41 \pm 0.01$ & $99.1 \pm 0.4$ & $70.6 \pm 1.5$ & $567 \pm 21$ \\
\hline ProAir, $15 \mathrm{~s}$ & $2.29 \pm 0.08$ & $1.43 \pm 0.03$ & $99.3 \pm 0.5$ & $69.3 \pm 2.3$ & $528 \pm 19$ \\
\hline Proventil, $60 \mathrm{~s}$ & $2.21 \pm 0.11$ & $1.42 \pm 0.08$ & $99.7 \pm 0.1$ & $75 \pm 4.2$ & $606 \pm 37$ \\
\hline Proventil, $30 \mathrm{~s}$ & $2.29 \pm 0.03$ & $1.35 \pm 0$ & $99.5 \pm 0.3$ & $77.1 \pm 0.5$ & $515 \pm 21^{*}$ \\
\hline Proventil, $15 \mathrm{~s}$ & $2.30 \pm 0.01$ & $1.39 \pm 0.03$ & $99.6 \pm 0.3$ & $75.2 \pm 0.6$ & $609 \pm 39$ \\
\hline
\end{tabular}

$\mathrm{FPM}=$ fine-particle mass 
respectively. The differences do not appear to be clinically relevant.

There were no significant differences in GSD among the 3 time intervals for ProAir $(P=.29)$. Ventolin had a larger GSD with a 30-s interval than with $60 \mathrm{~s}(P=.02)$, and Proventil showed the opposite effect $(P=.048)$. The differences between the smallest and largest GSD were 0.09, 0.10, and 0.19 for Ventolin, ProAir, and Proventil, respectively. All aerosols were heterodisperse, and the differences do not appear to be clinically relevant.

There were no significant differences in percentage $<5 \mu \mathrm{m}$ among the 3 time intervals for $\operatorname{ProAir}(P=.65)$ and Proventil $(P=.062)$. However, the percentage $<5 \mu \mathrm{m}$

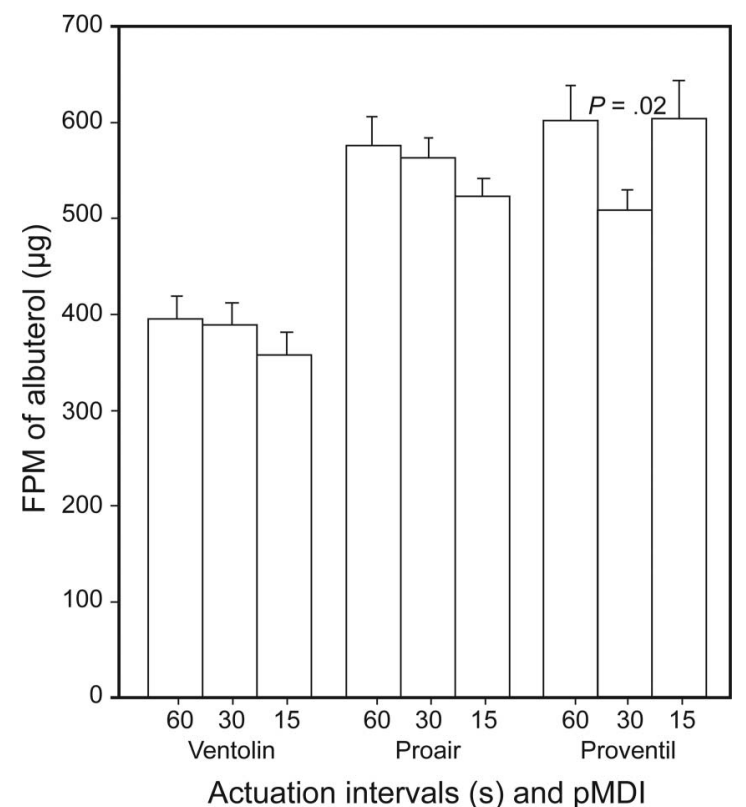

Fig. 3. Fine-particle mass (FPM) of albuterol hydrofluroalkane pressurized metered-dose inhaler (pMDI) coupled to a valved holding chamber. Bars show means, and error bars represent SD. $P$ value is fine-particle mass difference from a 60 -s interval. for Ventolin was larger for a 60-s interval than for a 30 -s interval $(P=.009)$. Variations from 60 -s values were $<15 \%$ for all brands.

There were no significant differences in percentage 1$3 \mu \mathrm{m}$ among the 3 time intervals for ProAir $(P=.69)$ and Proventil $(P=.063)$. The percentage $1-3 \mu \mathrm{m}$ for Ventolin was smaller for the 30-s than for the 60-s interval $(P=.01)$. Variations from 60 -s values were $<15 \%$ for all brands.

There were no significant differences in fine-particle mass among the different actuation intervals for Ventolin $(P=.07)$ and ProAir $(P=.68)($ Fig. 4). Proventil showed

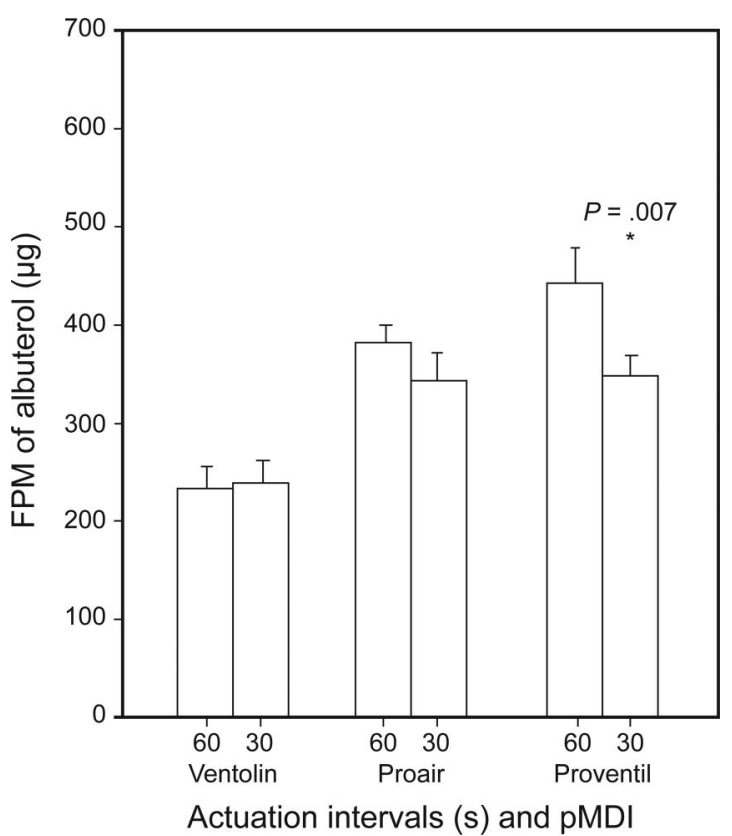

Fig. 4. Fine-particle mass (FPM) of albuterol hydrofluroalkane pressurized metered-dose inhaler (pMDI) coupled to a valved holding chamber after a 10-s delay between actuation and measurement was introduced. Bars show means, and error bars represent SD. $P$ value is fine-particle mass difference from a 60 -s interval. * Variation from $60 \mathrm{~s}$ is $>15 \%$.

Table 3. Aerosol Characteristics of Pressurized Metered-Dose Inhaler Coupled to a Valved Holding Chamber Actuated at Different Interval Periods When a 10-s Delay Between Actuation and Testing Was Introduced*

\begin{tabular}{|c|c|c|c|c|c|}
\hline Dose & MMAD $(\mu \mathrm{m})$ & GSD & $<5 \mu \mathrm{m}(\%)$ & $1-3 \mu \mathrm{m}(\%)$ & $\mathrm{FPM}(\mu \mathrm{g})$ \\
\hline Ventolin, $60 \mathrm{~s}$ & $2.39 \pm 0.05$ & $1.41(0.02)$ & $99.1(0.6)$ & $65.5(3)$ & $233(22)$ \\
\hline Ventolin, $30 \mathrm{~s}$ & $2.39 \pm 0.08$ & $1.46(0.01)$ & $96.7(1.3)^{*}$ & $60.4(1.1)^{*}$ & $240(22)$ \\
\hline ProAir, $60 \mathrm{~s}$ & $2.21 \pm 0.07$ & $1.43(0.04)$ & $99.6(0.1)$ & $70.9(3.5)$ & $383(18)$ \\
\hline ProAir, $30 \mathrm{~s}$ & $2.29 \pm 0.03$ & $1.40(0.02)^{*}$ & $99.6(0.1)$ & $71.5(1.5)$ & $344(30)$ \\
\hline Proventil, $60 \mathrm{~s}$ & $2.17 \pm 0.04$ & $1.48(0.08)$ & $96.1(2.5)$ & $67.4(6.2)$ & $443(37)$ \\
\hline Proventil, $30 \mathrm{~s}$ & $2.26 \pm 0.04 *$ & $1.35(0.01)^{*}$ & $99.7(0)$ & $78.4(1.3)$ & $349(20) * \dagger$ \\
\hline
\end{tabular}

$\overline{\text { Results are mean } \pm \text { SD }}$

$*$ Different from 60 -s interval $(P<.05)$

$\uparrow$ Variation from 60 -s values is $>15 \%$.

MMAD = mass median aerodynamic diameter

$\mathrm{GSD}=$ geometric standard deviation

FPM $=$ fine-particle mass 
a decrease of $21 \%$ in fine-particle mass for the $30 \mathrm{~s}$ $(P=.007)$. Variations from $60-\mathrm{s}$ values for Ventolin and ProAir were $<15 \%$. Comparison of fine-particle mass among brands showed that Proventil was $>$ ProAir $>$ Ventolin at the 60-s interval $(P \leq .03)$. Comparison of fineparticle mass among brands showed that Proventil $=$ ProAir $(P=.96)>$ Ventolin at the 30 -s interval $(P<.001)$. The introduction of a 10-s delay resulted in a significant reduction in fine-particle mass for all brands (ProAir 34-39\%, Ventolin 39-42\%, and Proventil 27-32\%).

\section{Discussion}

We compared the aerosol characteristics of 3 brands of albuterol sulfate HFA when the intervals between actuations were 60,30 , and $15 \mathrm{~s}$, and the pMDI was operated alone, coupled to a valved holding chamber, and coupled with a valved holding chamber while introducing a 10-s delay between actuation and measurement. We found that, in general, there were either no differences or no clinically relevant differences in the aerosol characteristics of albuterol HFA and ProAir when used alone, with a valved holding chamber, and with a valved holding chamber with a 10-s delay. However, Proventil had changes in percentage $<5 \mu \mathrm{m}$ (30 and $15 \mathrm{~s}$ ), percentage $1-3 \mu \mathrm{m}$ (15 s), and fine-particle mass $(30 \mathrm{~s})$ when used alone and in fineparticle mass when used with a valved holding chamber with a 10-s delay. Proventil had the highest fine-particle mass, followed by ProAir. The latter appears to be the most stable of the different brands of albuterol HFA pMDI tested.

The aerosol characteristics of the pMDI alone of Ventolin and ProAir are similar to those reported by McCabe et $\mathrm{al}^{9}$ They reported an MMAD/GSD/fine-particle dose (calculated as mass for percentage $<5 \mu \mathrm{m}$ ) for Ventolin alone of $2.4 \mu \mathrm{m} / 2.0 / 26 \mu \mathrm{g}$, compared with our findings of $2.39 \mu \mathrm{m} / 1.41 / 29.3 \mu \mathrm{g}$. Similarly, they reported MMAD/GSD/fine-particle dose for ProAir alone of $2.3 \mu \mathrm{m} / 1.6 / 53 \mu \mathrm{g}$, and we measured $2.21 \mu \mathrm{m} / 1.43 / 42.9 \mu \mathrm{g}$.

Slator et al ${ }^{12}$ compared the percentage of label claim of ProAir HFA coupled to several valved holding chambers, including one similar to the one we used. They evaluated several variables, including the effect of delay between actuation and inhalation. They reported that the emitted dose decreased by $20 \%$ when a 10 -s delay between actuation and measurement was introduced. We also found a significant effect of the delay resulting in a $34-39 \%$ decrease in fine-particle mass when compared with ProAir $\mathrm{pMDI} / \mathrm{valved}$ holding chamber. The same phenomenon was seen for Ventolin (39-42\%) and Proventil (27-32\%). Our data are also consistent with the findings of Rau et al, ${ }^{13}$ who compared fine-particle mass of Ventolin HFA used with several valved holding chambers, including one similar to the one we used. They reported that increasing the delay between actuation and inhalation from 2 to $5 \mathrm{~s}$ re- sulted in a $20 \%$ decrease in fine-particle mass. This has to be kept in mind when diagnostic studies, such as response to bronchodilators, are done.

Hautman et $\mathrm{al}^{7}$ compared fine-particle mass of albuterol of the same inhalers we studied. They used intervals between actuations of $15,30,60$, and $120 \mathrm{~s}$ and reported that fine-particle mass increased for ProAir alone and for Proventil and Ventolin with and without a valved holding chamber when interval time was increased from 15 to $120 \mathrm{~s}$. Similarly, we found that the introduction of a delay resulted in a significant increase in fine-particle mass. The authors also reported that the use of a valved holding chamber results in an increase in fine-particle mass that is modest for ProAir but large for Ventolin and Proventil. Our data are consistent with their report. We speculate that the difference in magnitude seen between ProAir and the others is because its aerosol velocity is slower than the others. ${ }^{7,9}$ Hautman et $\mathrm{al}^{7}$ limited the particle size distribution analysis to fine-particle mass. Our study provides a more complete description of the aerosols and also introduces the effect of delay between actuation and measurement as novel data.

The clinical implications of our findings are severalfold. First, albuterol HFA pMDI either alone or with a valved holding chamber could be actuated with intervals $<60 \mathrm{~s}$ without affecting the aerosol characteristics. This would allow an increase in productivity for the practitioner administering the aerosol. Second, the use of a small-volume valved holding chamber made of nonelectrostatic material could optimize drug delivery. Finally, delays between actuation and inhalation should be avoided because of the negative effect on fine-particle mass. These data cannot be extrapolated to add-on devices that require the removal of the canister from the plastic actuator to be used and/or other valved holding chambers (ie, different volume or made from nonconductive material).

One limitation of our study is that we did not use any mechanical system to introduce the delay between actuation and testing. ${ }^{12,13}$ Another potential limitation of this study is that breathing simulation was not coupled to the measurement of particle size.

\section{Conclusions}

Decreasing the interval between actuations from $60 \mathrm{~s}$ to 30 and $15 \mathrm{~s}$ does not seem to affect the aerosol characteristics of ProAir and Ventolin. Although some changes were noticed for Proventil when decreasing the interval between actuations from $60 \mathrm{~s}$ to 30 and $15 \mathrm{~s}$, the pMDI outperformed Ventolin that had the lowest fine-particle mass. Although the use of a valved holding chamber increased fine-particle mass, introduction of a 10-s delay between actuation and inhalation significantly reduced fine-particle mass. 


\section{Timing of Albuterol HFA Inhaler Actuations}

\section{REFERENCES}

1. Centers for Disease Control and Prevention. Most Recent Asthma Data. http://www.cdc.gov/asthma/most_recent_data.htm. Accessed April 25, 2017.

2. National Institutes of Health. National Heart, Lung, and Blood Institute. National Asthma Education and Prevention Program. Expert Panel Report 3: guidelines for the diagnosis and management of asthma. Aug 2007. NIH publication no. 07-4051. http://www.nhlbi. nih.gov/guidelines/asthma/index.htm. Accessed December 30, 2015.

3. Dolovich MB, Ahrens RC, Hess DR, Anderson P, Dhand R, Rau JL, et al. Device selection and outcomes of aerosol therapy: evidencebased guidelines: American College of Chest Physicians/American College of Asthma, Allergy, and Immunology. Chest 2005;127(1): 335-371.

4. VentolinR HFA package insert. Highlights of prescribing information. Philadelphia, Pennsylvania: GlaxoSmithKline; June 2009.

5. ProAirR HFA package insert. Highlights of prescribing information. Horsham, Pennsylvania: Teva Respiratory; Revised July 2010.

6. ProventilR HFA package insert. Prescribing information. Kenilworth, New Jersey: Schering-Plough Corporation; Revised November 2010.

7. Hautmann J, Godoy SE, Marshik P, Chand R, McConville J, Krishna $\mathrm{S}$, et al. Effect of time between actuation on the dose variability for three metered dose inhalers. Respir Drug Deliv Eur 2013;2:429-434.
8. Clark DJ, Lipworth BJ. Effect of multiple actuations, delayed inhalation and antistatic treatment on the lung bioavailability of salbutamol via a spacer device. Thorax 1996;51(10):981-984.

9. McCabe JC, Koppenhagen F, Blair J, Zeng XM. ProAir HFA delivers warmer, lower-impact, longer-duration plumes containing higher fine particle dose than Ventolin HFA. J Aerosol Med and Pulm Drug Deliv 2012;25(2):104-109.

10. Marple VA, Olson BA, Santhanakrishnan K, Mitchell JP, Murray SC, Hudson-Curtis BL. Next generation pharmaceutical impactor (a new impactor for pharmaceutical inhaler testing). Part II: Archival calibration. J Aerosol Med 2003;16(3):301-324.

11. Kelly HW, Ahrens RC, Holmes M, Stevens AL, Vandermeer AK, Garris T, Reisner C. Evaluation of particle size distribution of salmeterol administered via metered-dose inhaler with and without valved holding chambers. Ann Allergy Asthma Immunol 2001;87(6): 482-487.

12. Slator L, von Hollen D, Sandell D, Hatley RH. In vitro comparison of the effect of inhalation delay and flow rate on the emitted dose from three valved holding chambers. J Aerosol Med Pulm Drug Deliv 2014;27 Suppl 1:S37-S43.

13. Rau JL, Coppolo DP, Nagel MW, Avvakoumova VI, Doyle CC, Wiersema KJ, Mitchell JP. The importance of nonelectrostatic materials in holding chambers for delivery of hydrofluoroalkane albuterol. Respir Care 2006;51(5):503-510.

This article is approved for Continuing Respiratory Care Education credit. For information and to obtain your CRCE

(free to AARC members) visit www.rcjournal.com 